\title{
ASSESSMENT OF NURSES KNOWLEDGE TOWARDS POST THYROIDECTOMY MANAGEMENT IN NINEVEH GOVERNORATE HOSPITALS Ali Ismael Sulaiman ${ }^{1}$,Taha Hassan Al- Saigh ${ }^{2}$
}

\section{Abstract}

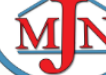

Background and Aim: Complications that may associated thyroidectomy can often be lifethreatening. It is important that nurses have the knowledge and skills to manage the patients with thyroidectomy and potential complications. The study aimed to assess nurses' knowledge towards post thyroidectomy management in Nineveh governorate hospitals.

Material and Methods: a descriptive cross-sectional study was performed in two governmental hospitals are included in the study (Tal Afar General Hospital and Al-Salam Teaching Hospital). The study has been conducted from $7^{\text {th }}$ of October to $30^{\text {th }}$ of December 2019. The study sample was randomly selected consisting of (60) nurses from both hospitals. A special questionnaire tool was constructed by the researcher, this questionnaire tool consisted of two parts, nurses' demographic characteristics and questions for knowledge about post thyroidectomy management in the form of multiple choice questions. The data were analyzed through the application of descriptive statistical analysis that included frequency, percentage.

Result: The study indicated that $43.3 \%$ of the study sample age were20-29 years, with high percentages $55.0 \%$ were females, $40.0 \%$ of them were at secondary and institution educational level. Concerning of their knowledge majority $43.3 \%$ of them were at not acceptable level $25.0 \%$ of them were at fail level which mean $68.3 \%$ of the nurses have incorrect responses.

Conclusion: The findings of the current study concludes that inadequacy of nurses' knowledge in the medical wards, intensive care units, and recovery room toward postoperative management for patient with thyroidectomy.

Recommendation: conducting educational program for nurses about post-operative management for patient with thyroidectomy to improve nurses' knowledge and skills.

Key words: thyroidectomy, management, complications

\footnotetext{
${ }^{1}$ B.Sc. Nursing, MSN Candidate, College of Nursing, University of Mosul. Iraq. ali.ismael2324@gmail.com

${ }^{2}$ Assistant professor, College of Medicine, University of Nineveh, Iraq
} 


\section{Introduction}

Thyroid operations increased dramatically and reached threefold over the past 3 decades ago; in the United States 118 - 166 thousand patients undergoing thyroidectomy per year for either benign or malignant thyroid tumors(Chandrasekhar et al., 2013). While in England over 13 thousand thyroid operation done annually (Stedman, Chew, Truran, Lim, \& Balasubramanian, 2018). It is usually performed for both sex clients but in female more(Liu, Masterson, Fish, Jani, \& Chatterjee, 2015).Over the past twenty five year $s$, the incidence of thyroid malignant tumors has steadily increased. Therefore not surprisingly, thyroid-ectomy rates have increased during this period(Davies \& Welch, 2014).Thyroidectomy is one of the most common neck and endocrine surgeries that performed today, because of technological advances in the thyroid surgeries the mortality and morbidity rates are low but some longterm complications that occur post thyroidectomy continue to represent a health and social problem(KG \& Shantharam, 2013). Thyroid carcinoma consider the most common endocrine disorders that need thyroidectomy with very good survival outcome(Kandil, Noureldine, Abbas, \& Tufano, 2013). In general, the patient who undergoing thyroidectomy need more precise preoperative preparations because if the pre-operative is inadequate, postoperative compli-cations like hemorrhage, dyspnea, recurrent nerve injury, parathyroid injury and other serious post-operative complications will occur(Filho \& Kowalski, 2005; Heydari, Farrin-gton, \& Taylor, 2011).Post thyroidectomy frequent compli-cations usually occurs after either total or partial thyroidectomy due to either surgical procedure itself or the secondary metabolic disturbances includes hemorrhage, wound infection, hypoparathyroidism and recurrent laryngeal nerve (RLN) injury, while post thyroidectomy less frequent complications involve thyroid storm(Zakaria et al., 2011; Christou \& Mathonnet, 2013).Preoperative and postoperative nursing care it is important because inadequate preparation of patient to thyroid surgery and non-proper postoperative nursing care have a serious influence on patient's recovery directly, put patients live in dangerous and then affect the patient's quality of life. Therefore, the nursing manag-ement before and after thyroid surgeries carried out by observing the patient condition, assist and cooperate with surgeon for management and aggressively deal with severe post thyroidectomy complications(Miller, 
2007). Providing information and assisting the patients to make right health decisions and motivating the patient to learn about the health consider a vital nursing role so, implementation of thyroidectomy nursing care guidelines for patients may cause improve patient's outcomes by promoting patient compliance with medical treatment regimens and improving healthy lifestyles (Delamater et al., 2001). The study aimed to assess nurses' knowledge towards post thyroidectomy management in Nineveh governorate hospitals. The purpose of this study was firstly, to assess nurses' knowl-edge towards management for patients with thyroidectomy, second, to find out if there is any relationship between nurses' knowledge towards post thy- roidectomy management and their demographical characteristics

\section{MATERIAL AND METHODS:}

a descriptive cross-sectional study was performed in two governmental hospitals are included in the study (Tal Afar General Hospital and Al-Salam Teaching Hospital). The study sample was randomly selected consisting of (60) nurses from both hospitals. A special questionnaire tool was constructed by the researcher, this questionnaire tool consisted of two parts, the demographic characteristics and questions for knowledge about post thyroidectomy management in the form of multiple-choice questions. The data were analyzed through the application of descriptive statistical analysis that included frequency, percentage. 


\section{Results:}

Table (1): The Demographic Variables of the Respondents in the Study

\begin{tabular}{|c|c|c|c|}
\hline Variables & Items & F. & $\%$ \\
\hline \multirow{3}{*}{ Name of the Teaching hospital } & Telafar & 30 & 50.0 \\
\hline & Al-Salam & 30 & 50.0 \\
\hline & 20-29 & 26 & 43.3 \\
\hline \multirow[t]{3}{*}{ Age(years) } & $30-39$ & 21 & 35.0 \\
\hline & $40-49$ & 11 & 18.3 \\
\hline & 50-more & 2 & 3.3 \\
\hline \multirow{3}{*}{ Gender } & Male & 27 & 45.0 \\
\hline & Female & 33 & $\mathbf{5 5 . 0}$ \\
\hline & Secondary & 24 & 40.0 \\
\hline \multirow[t]{3}{*}{ Level of Education } & Institution & 24 & 40.0 \\
\hline & College & 12 & 20.0 \\
\hline & Less than 5 years & 21 & 35.0 \\
\hline \multirow{4}{*}{ Years of employment } & $5-10$ & 23 & 38.3 \\
\hline & $11-15$ & 12 & 20.0 \\
\hline & More than 15 years & 4 & 6.7 \\
\hline & General Surgical Ward & 30 & $\mathbf{5 0 . 0}$ \\
\hline \multirow[t]{2}{*}{ Working Place/site } & Intensive Care Unit & 24 & 40.0 \\
\hline & Recovery Room & 6 & 10.0 \\
\hline \multirow{3}{*}{ Enrolment Training courses } & No & 60 & 100.0 \\
\hline & Yes & 0 & 0.0 \\
\hline & & 60 & 100.0 \\
\hline
\end{tabular}

Table (2): Statistical Total Knowledge Results for Study sample in concerning the post thyroidectomy management

\begin{tabular}{|c|c|c|c|}
\hline & Estimate & F. & $\%$ \\
\hline \multirow{5}{*}{ Knowledge } & Fail & 15 & 25.0 \\
\hline & Not acceptable & 26 & 43.3 \\
\hline & Acceptable & 14 & 23.3 \\
\hline & Good & 5 & 8.4 \\
\hline & Excellent & 0 & 0.0 \\
\hline \multicolumn{2}{|c|}{ The Total } & 60 & 100.0 \\
\hline
\end{tabular}


Table (3): Statistical Relationships between the Demographic Variables of Nurses and their knowledge concerning the post thyroidectomy management

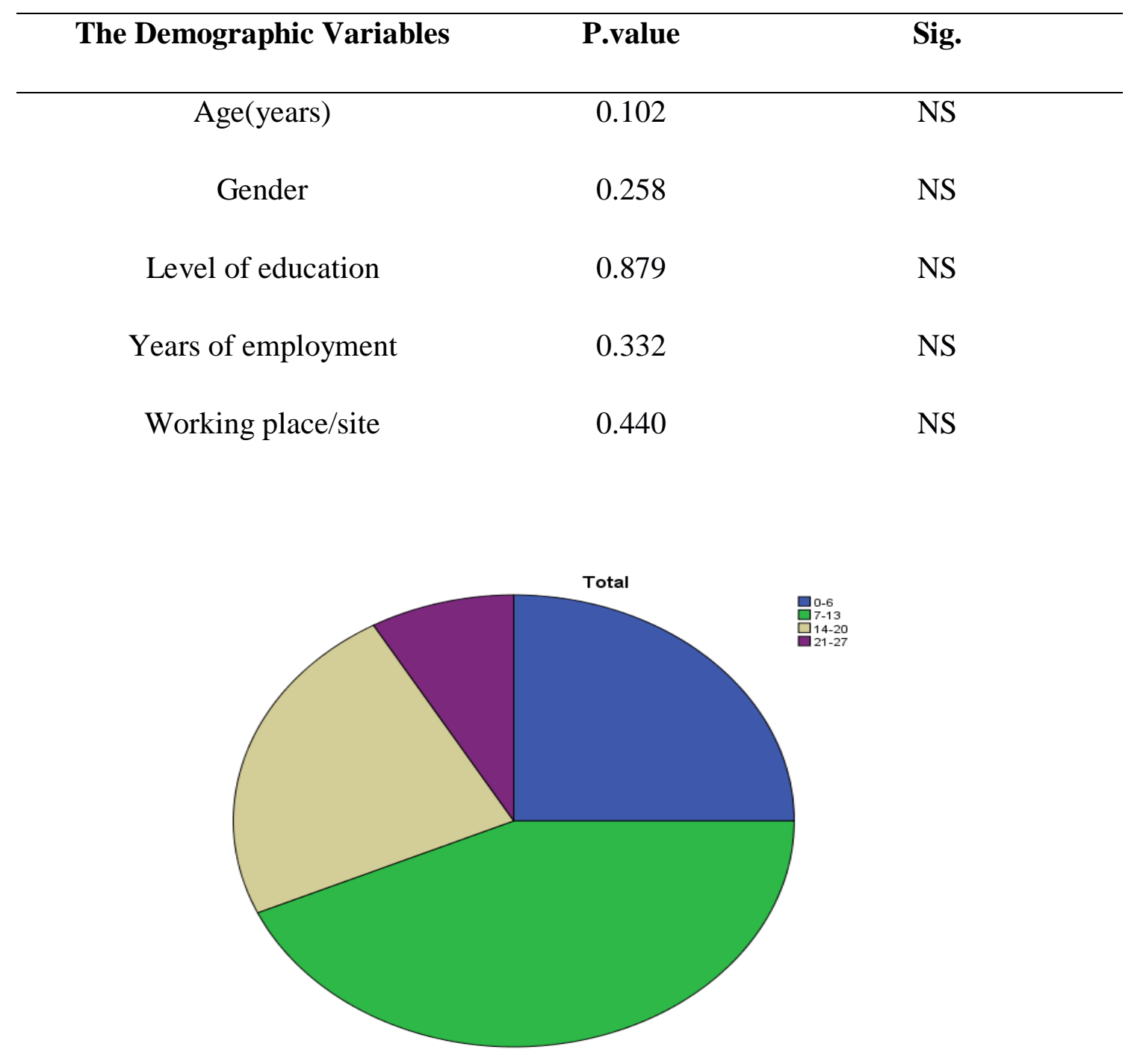

Figure (1) Distribution of total knowledge results for the sample 


\section{DISCUSSION}

The (Table1) shows that the majority $43.3 \%$ of the sample at age $20-29$, the high percentages $55.0 \%$ of them were females, and most of them $40.0 \%$ were at secondary and institution stage of educational level. These results were in agreement with the study conducted by (Desoky, \& Ghanem, 2009), who confirmed that the mean age of nurses was 29.53 and supported by (Hend et al., 2012) which reported that majority of nurses $87.4 \%$ in the study were females. This age group which considered as an adult youth, so the nurses in this age group can provide nursing care efficiently and correctly.

Regarding to years of employment the current study result show that $38.3 \%$ of the sample have between 5-10 years. Since majority of nurses who have many service years, they move to work in primary health centers, so the younger nurse's stay in the hospital care. With regard to work site majority $50.0 \%$ of the sample were working in General surgical ward. This because the target population in the present study were the nurses who working in surgical wards, Intensive care units, recovery room. The present study confirmed that all of the study and control group have no previous training course regarding thyroidectomy management. This may be due to the policy of our hospitals of preparing programs to improve nurses' knowledge regarding post thyroidectomy management. The table (2) expressions the statistical total knowledge results for the study sample concerning the post thyroidectomy management, which confirmed that the majority $43.3 \%$ of them were at not acceptable level, and $25 \%$ of them were at fail level which mean the high percentage $68.3 \%$ of the nurses have incorrect responses. The table (3) presents statistical relationships of the current study between the demographic variables of nurses and their knowledge regarding post thyroidectomy management. There are not significant relationships between nurse's knowledge with all their demographical variables. And accordingly, it could be concluded that the questionnaire of studying assessment of nurses' knowledge could be generalized on the studied population even though differences within socio-demographical characteristics variables of studied subjects would be in the study group. 


\section{REFERENCES}

Chandrasekhar, S. S., Randolph, G. W., Seidman, M. D., Rosenfeld, R. M., Angelos, P., Barkmeier-Kraemer, J. ,Hanks, J. (2013). Clinical practice guideline: improving voice outcomes after thyroid surgery. Otolaryngology-Head and Neck Surgery, 148(6_suppl), S1-S37

Christou, N., \& Mathonnet, M. (2013). Complications after total thyroidectomy. Journal of Visceral Surgery, 150(4), 249-256.

Davies, L., \& Welch, H. G. (2014). Current thyroid cancer trends in the United States. JAMA Otolaryngology-Head \& Neck Surgery, 140(4), 317-322.

Delamater, A. M., Jacobson, A. M., Anderson, B., Cox, D., Fisher, L., Lustman, P., Wysocki, T. (2001). Psychosocial therapies in diabetes: report of the Psychosocial Therapies Working Group. Diabetes Care, 24(7), 1286-1292.

Desoky, A. A., Mohamed, M. A., Ahmed, M. T., \& Ghanem, H. M. (2009). Assessment of nurses'performance for patients undergoing thyroidectomy at assiut university hospital. AAMJ, $7(2), 18,223-227$

Filho, J. G., \& Kowalski, L. P. (2005). Surgical complications after thyroid surgery performed in a cancer hospital. OtolaryngologyHead and Neck Surgery, 132(3), 490-494.

Hend M. Elazazay, Amany L. Abdelazez and Omibrahem A. Elsaie: Effect of Cardiopulmonary Resuscitation
Training Program on Nurses Knowledge and Practicelife Science Journal 2012;9(4)

Heydari, S., Farrington, N., \& Taylor, B. (2011). Complications following thyroid surgery. International Journal of Surgery, 7(9), 503.

Kandil, E., Noureldine, S. I., Abbas, A., \& Tufano, R. P. (2013). The impact of surgical volume on patient outcomes following thyroid surgery. Surgery, 154(6), 13461353.

KG, S. B., \& Shantharam, L. (2013). A study of complications of thyroidectomy. Int J Cur Res Rev, 5(17).

Liu, Z. W., Masterson, L., Fish, B., Jani, P., \& Chatterjee, K. (2015). Thyroid surgery for Graves' disease and Graves' ophthalmopathy. Cochrane Database of Systematic Reviews, (11).

Miller, J. (2007). Diabetes and thyroid disease: Nursing care to improve outcomes for patients living in poverty. Nursing Clin, 42(1), 113125.

Stedman, T., Chew, P., Truran, P., Lim, C. B., \& Balasubramanian, S. P. (2018). Modification, validation and implementation of a protocol for post-thyroidectomy hypocalcaemia. The Annals of The Royal College of Surgeons of England, 100(2), 135-139.

Zakaria, H. M., Al Awad, N. A., Al Kreedes, A. S., Al-Mulhim, A. M. A., AlSharway, M. A., Hadi, M. A., \& Al Sayyah, A. A. (2011). Recurrent laryngeal nerve injury in thyroid surgery. Oman Medical Journal, 26(1), 34. 